\title{
Comprehensive identification of genes driven by ERV9-LTRs reveals TNFRSF10B as a re-activatable mediator of testicular cancer cell death
}

\author{
U Beyer ${ }^{1,2,5}$, SK Krönung ${ }^{1,5}$, A Leha ${ }^{3}$, L Walter ${ }^{4}$ and M Dobbelstein ${ }^{\star, 1}$
}

The long terminal repeat (LTR) of human endogenous retrovirus type 9 (ERV9) acts as a germline-specific promoter that induces the expression of a proapoptotic isoform of the tumor suppressor homologue p63, GTAp63, in male germline cells. Testicular cancer cells silence this promoter, but inhibitors of histone deacetylases (HDACs) restore GTAp63 expression and give rise to apoptosis. We show here that numerous additional transcripts throughout the genome are driven by related ERV9-LTRs. 3' Rapid amplification of cDNA ends (3'RACE) was combined with next-generation sequencing to establish a large set of such mRNAs. HDAC inhibitors induce these ERV9-LTR-driven genes but not the LTRs from other ERVs. In particular, a transcript encoding the death receptor DR5 originates from an ERV9-LTR inserted upstream of the protein coding regions of the TNFRSF10B gene, and it shows an expression pattern similar to GTAp63. When treating testicular cancer cells with HDAC inhibitors as well as the death ligand TNF-related apoptosis-inducing ligand (TRAIL), rapid cell death was observed, which depended on TNFRSF10B expression. HDAC inhibitors also cooperate with cisplatin (CDDP) to promote apoptosis in testicular cancer cells. ERV9-LTRs not only drive a large set of human transcripts, but a subset of them acts in a proapoptotic manner. We propose that this avoids the survival of damaged germ cells. HDAC inhibition represents a strategy of restoring the expression of a class of ERV9-LTR-mediated genes in testicular cancer cells, thereby re-enabling tumor suppression.

Cell Death and Differentiation (2016) 23, 64-75; doi:10.1038/cdd.2015.68; published online 29 May 2015

Long terminal repeats (LTRs) derived from endogenous retroviruses represent $8 \%$ of the human genome. ${ }^{1}$ LTRs are mostly 'selfish' without obvious use for the host, however, during evolution, some LTR-derived promoters were inserted upstream of functional genes, possibly regulating gene expression to benefit the host organism. ${ }^{2}$

We have recently identified a prominent example of such an LTR-driven gene. The human tumor suppressor TP63 carries an endogenous retrovirus type 9 (ERV9)-LTR upstream of its protein-coding sequences. ${ }^{3}$ ERV9-LTR promoter activity is highest in human testis, and that is where a germline-specific, transcriptionally active (GTA) isoform of p63 is found. GTAp63 is capable of inducing apoptosis upon genotoxic stress, possibly contributing to enhanced protection of the germline from permanent damage to its genome.,

During the development of testicular cancer, GTAp63 is efficiently downregulated by transcriptional silencing. However, its transcription can be restored by inhibition of histone deacetylases (HDACs), ${ }^{3}$ and this treatment also induces apoptosis. These findings at least suggest an alternative route of treating testicular cancer, although this would require clinical validation. Of note, however, the currently available treatment of this cancer already confers a high cure rate, making it difficult to balance risks and benefits when introducing new treatment regimens.

The ERV9-LTR promoter activity in the germline and its inducibility by HDAC inhibitors (HDACi) prompted us to test whether more human genes are subject to regulation by ERV9-LTRs that inserted upstream of them. Furthermore, we asked whether additional genes of this kind contribute to apoptosis, particularly in the context of HDAC inhibition in germ cell tumors. Besides TP63, ERV9-LTRs were also previously observed to induce the expression of ZNF80,5,6 $A D H 1 C{ }^{7}{ }^{7} D_{R S 2^{8}}$ and $I R G M .^{9}$ Within the hemoglobin beta locus, an ERV9-LTR initiates transcription from the locus control region. ${ }^{10-12}$ The fact that ERV9-LTRs are inserted roughly 3000 times in the human genome, ${ }^{13,14}$ raises the possibility that more genes are regulated by them.

Using rapid amplification of cDNA ends (RACE) and nextgeneration sequencing (NGS), we identified a large set of

${ }^{1}$ Institute of Molecular Oncology, Göttingen Center of Molecular Biosciences (GZMB), University of Göttingen, Göttingen, D-37077, Germany; ${ }^{2}$ Department of Human Genetics, Hannover Medical School, Hannover, D-30625, Germany; ${ }^{3}$ Department of Medical Statistics, University Göttingen, Göttingen, D-37033, Germany and ${ }^{4}$ Primate Genetics Laboratory, German Primate Center, Göttingen, D-37077, Germany

${ }^{*}$ Corresponding author: M Dobbelstein, Institute of Molecular Oncology, University of Göttingen, Göttingen Center of Molecular Biosciences (GZMB), Justus von Liebig Weg 11, Göttingen, Niedersachsen, D-37077, Germany, Tel: +0049 55139 13840, Fax: +0049 55139 13713, E-mail: mdobbel@uni-goettingen.de

${ }^{5}$ These authors contributed equally to this work.

Abbreviations: cDDP, Cisplatin; CHOP, CCAAT/-enhancer binding protein homologous protein; Cl, Combination Index; DR5, Death receptor 5; ER, Endoplasmatic reticulum; ERV9, Endogenous retrovirus type 9; FDA, Food and Drug Administration; GO, Gene ontology; GTAp63, Germline-specific transcriptionally active p63; HDAC, Histone deacetylase; HDACi, Histone deacetylase inhibitor; HERV, Human endogenous retrovirus; LTR, Long terminal repeat; MEHP, Mono-(2-ethylhexyl) phthalate; MID, Multiple identifyer; NF-Y, Nuclear factor Y; NGS, Next-generation sequencing; PARP-1, Poly (ADP-ribose) polymerase 1; RACE, Rapid amplification of cDNA ends; SAHA, Suberoylanilide hydroxamic acid; Sp1, Specificity protein 1; TNF $\alpha$, Tumor necrosis factor alpha; TRAIL, TNF-related apoptosis-inducing ligand; TSA, Trichostatin A Received 12.11.14; revised 04.4.15; accepted 16.4.15; Edited by G Melino; published online 29.5.15 
ERV9-LTR-derived transcripts. One of them originates from the gene TNFRSF10B that encodes the death receptor 5 (DR5) alias Killer. Like GTAp63, LTR-driven TNFRSF10B transcripts are found in testicular cells and are induced by HDAC inhibition in testicular tumor cells to mediate apoptosis. Combined treatment of testicular cancer cells with an HDACi and the clinically used therapeutic drug cDDP synergistically induced cancer cell death.

\section{Results}

ERV9-LTR-driven genes are induced by HDACis in testicular cancer cells. First, a BLAST search of the human genome, using the LTR sequence upstream of TP63, ${ }^{3}$ identified a set of candidate genes for ERV9-LTR-mediated regulation, in particular CGREF1, GBP5, IRGM, KCNN2 and PGPEP1L (Supplementary Figure S1 and Supplementary Table S1). This search was not meant to be comprehensive, but the candidates that were found served to examine the characteristics of ERV9-LTR-driven gene expression. In particular, we tested whether they would respond to HDACi in testicular cancer cells, as GTAp63 did. ${ }^{3}$

To reveal testicular HDACi-responsive genes, we analyzed mRNA expression patterns in $\mathrm{GH}$ testicular cancer cells treated with trichostatin A (TSA). As shown in Figures 1 a and b, more than 1400 genes were strongly induced by $18 \mathrm{~h}$ of treatment (5-fold induction or more), and for some genes, the hybridization signal was increased more than 50-fold (Figure 1b; Supplementary Tables S2 and S3). Strikingly, among the genes that responded most strongly, we found several of those that were previously found by BLAST search to carry an ERV9-LTR shortly upstream of their known exons (Figure 1b). Expression analysis by quantitative RT-PCR of the candidate LTR-driven genes showed a strong induction (several hundred fold) upon TSA treatment of $\mathrm{GH}$ cells (Figure 1c). Hence, a number of genes respond strongly to HDAC inhibition in $\mathrm{GH}$ cells, and among them, there are several that may be driven by an ERV9-LTR.

RACE reveals novel transcripts initiated by ERV9LTRs. We then used 3' RACE to identify a larger set of transcripts that originate from ERV9-LTRs, depicted in Figure 2a. We took advantage of the fact that all RNAs sought here have a common 5'-portion, that is, the transcribed region of the LTR. GH cells were treated with TSA for $18 \mathrm{~h}$ to enhance the synthesis of LTR-driven mRNAs. RNA from human testes served as an additional template for the RACE experiment. To strongly enrich for transcripts that contained an ERV-LTR sequence in their 5' end, we performed 3' RACE. A large pool of cDNAs was obtained using eight different PCR forward primers corresponding to the transcribed portion of the ERV9-LTR (Supplementary Table S4); four of those were degenerated, as the LTR sequences of different target genes are not identical. The pool of PCR products from each RACE reaction was visualized by agarose gel electrophoresis (Supplementary Figure S2) and then subjected to NGS. To generate the NGS library, a further amplification step of the RACE products with three different forward primers corresponding to the end of the ERV9-LTR was performed; the products from human testes were labeled with the multiple identifier MID1, those obtained from TSA-induced testicular cells were labeled with MID2. Two independent runs of sequencing resulted in 53343 or 74646 reads for run 1 or run 2 , respectively. Reads with a minimum frequency of 2 were sorted by their MID; the MID-specific sequence was cut and the remaining sequences were blasted against the human genome, obtaining 935 genes with an upstream ERV9-LTR promoter from normal testes, but only 280 genes in the TSA-treated testicular cancer GH cells (Supplementary Table S5). Interestingly, 86 transcripts of known genes were exclusively identified in the cancer-derived cells, but not in normal testis.

Strikingly, numerous genes corresponding to the ERV9LTR-driven transcripts had also been found inducible by HDAC inhibition in testicular cancer cells in our previous array hybridization. As displayed in the Venn diagram (Figure 2b), $1.8 \%(26 / 1428)$ of the genes induced by TSA in GH cells were also identified as expressing an ERV9-LTR-driven transcript upon the same treatment. Additionally, when comparing the LTR-associated transcripts from normal testes with the TSAinducible genes, $11.5 \%$ (50/434 genes) of the testicular LTRcontaining transcripts were found TSA-inducible in GH cells. Table 1 shows the 18 genes that express a transcript with a 5' end corresponding to the transcribed portion of the ERV9LTR in normal testis as well as TSA-treated testicular cancer cells, and that were also at least fivefold inducible by TSA in testicular cancer cells. Notably, and as expected, TP63 is among these genes.

Functional annotation of the 18 identified genes showed enrichment of the genes in two main processes: apoptosis and immunity. According to gene ontology (GO) annotations, 6 of 18 genes function in cell death regulation: CSF3, NR1H4, PTPN13, TMOD1, TNFRSF10B and TP63. Immunityassociated genes are CCR4, CSF3, IER3, NR1H4, TENM1 and TNFRSF10B. Using the PROTEOME tool (Biobase) we looked for further associations between our candidate genes. Figure $2 \mathrm{c}$ depicts those genes that are involved in cellular signaling pathways, along with the associated network. Notably, 9 of the 18 genes were associated with neoplasms in their annotations. Examples include TNFRSF10B, inducing apoptosis in various solid tumors, ${ }^{15-19}$ PTPN13 being upregulated in pancreatic cancer and Ewing sarcoma, ${ }^{20,21}$ or IER3 and CCR4 that have a role in myelodysplastic syndromes and lymphoma, respectively. ${ }^{22,23}$ In addition, TP63 contributes to tumorigenesis in several cancers. ${ }^{24}$

We conclude that a number of genes, mainly involved in immunity and apoptotic regulation, display similar expression characteristics as GTAp63 by virtue of an ERV9-LTR integrated upstream of them.

The TNFRSF10B locus contains an ERV9-LTR that gives rise to testicular transcripts. Treatment of testicular cancer cells with HDACi not only results in the induction of ERV9LTR promoter activity, but also in rapid apoptosis. ${ }^{3,25,26} \mathrm{We}$ therefore attempted to identify ERV9-LTR-driven genes that may contribute to programmed cell death. Strikingly, TNFRSF10B, encoding the death receptor 5, was among the HDACi-responsive and ERV9-LTR-downstream genes 
a

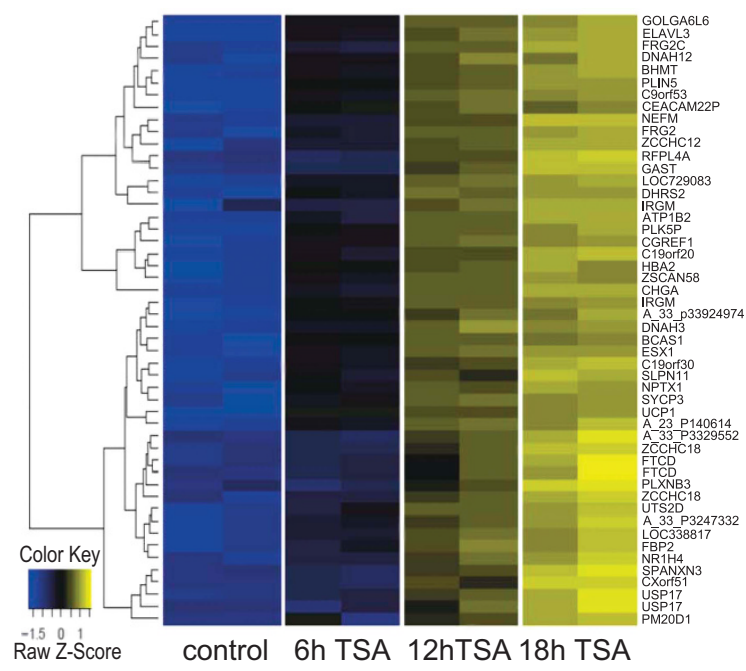

b

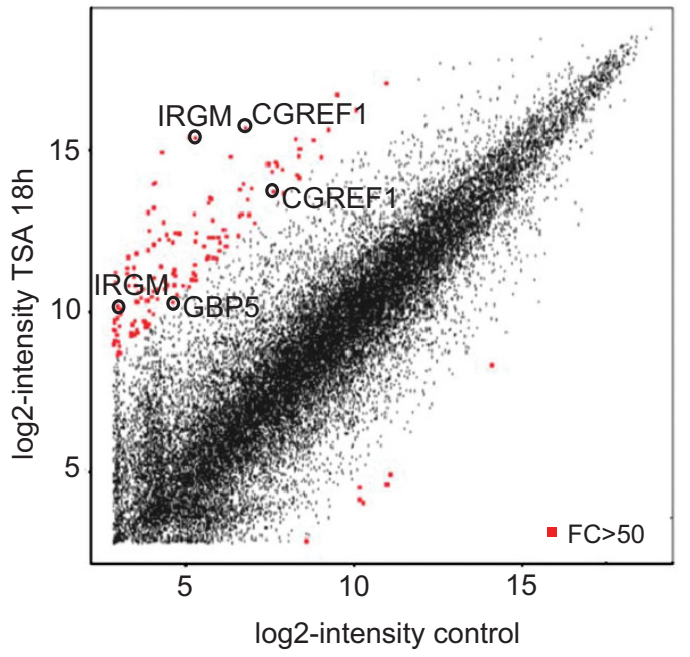

C
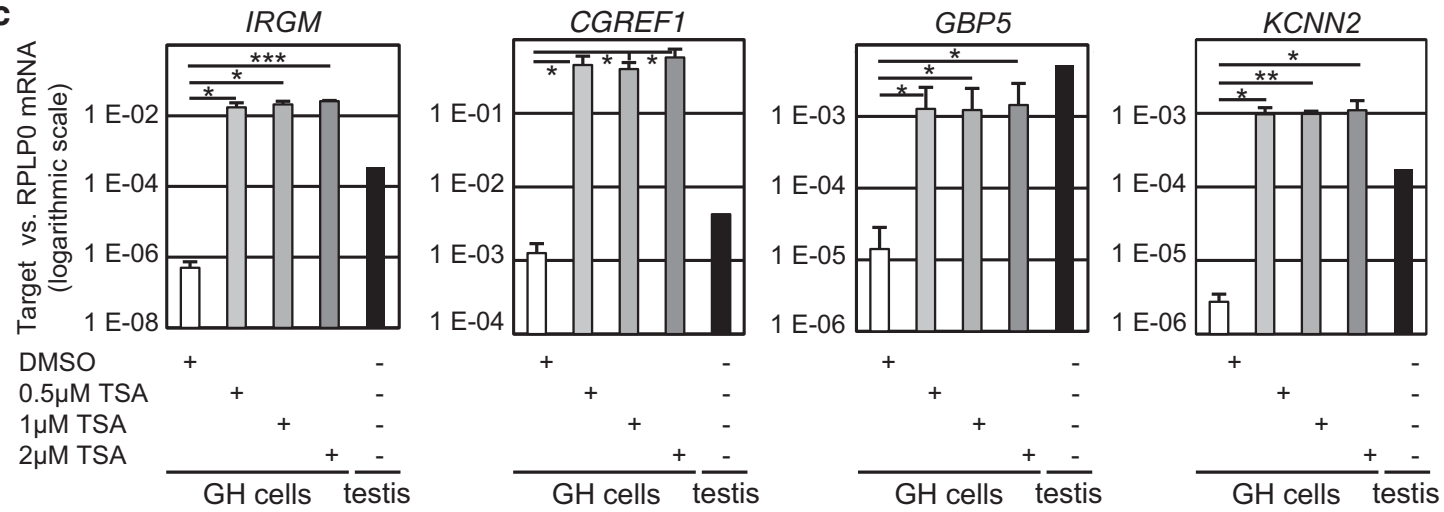

Figure 1 Induction of ERV9-LTR-associated genes by HDAC inhibition in testicular cancer cells. (a) Induction of gene expression in testicular cancer cells upon HDAC inhibition. Testicular tumor-derived cells of the line GH were treated with $500 \mathrm{nM}$ TSA for the indicated periods of time. Treatment with the solvent DMSO served as control. mRNA levels were determined by array hybridization. The heatmap shows the top 50 genes that were upregulated upon TSA treatment. Results from two independent experiments are shown. For every displayed gene, the Z-score was calculated: blue, the measured intensity of the sample is lower than the mean intensity of all samples; yellow, the measured intensity of the sample is higher than the mean intensity of all samples. Normalized expression data are shown in Supplementary Table S2. (b) Specific genes are upregulated by more than 50 -fold. The scatter plot depicts mean $\log _{2}$ intensities from the oligonucleotides on the array, each corresponding to a specific gene, comparing TSA-induced cells with control cells from the experiment described in (a). Red, differentially expressed transcripts with a fold change (FC) of at least 50; circles, genes that are situated close to an ERV9LTR in the genome (Supplementary Table S1). Logarithmic FC values of differentially expressed genes upon $18 \mathrm{~h}$ of TSA are shown in Supplementary Table S3. (c) Expression of candidate ERV9-LTR-driven genes (of (b) and Supplementary Table S1; array data are shown in Supplementary Tables S2 and S3) is enhanced by TSA treatment. GH cells were treated for $18 \mathrm{~h}$ with increasing concentrations of TSA or with the solvent DMSO. Quantification of target gene mRNA levels was performed by real-time RT-PCR, normalized to $R P L P 0$. Mean expression ratios of three independent experiments. $P$-values were calculated using Student's $t$-test (ns: $P>0.05,{ }^{*} P<0.05,{ }^{* \star} P<0.01,{ }^{* \star \star} P<0.001$ ). Expression levels in human normal testes were determined for comparison. Note the logarithmic scale

Figure 2 Identification of human transcripts that start at the ERV9-LTR using 3' RACE and NGS experiments. (a) Experimental design to identify human ERV9-LTR-driven transcripts. Human transcripts with LTR sequences at their 5 '-end were first reversely transcribed with a modified oligo(dT) primer, then amplified by RACE-PCR using diverse forward primers specific to the transcribed portion of the ERV9-LTR and the reverse Universal Primer Mix (UPM), obtaining a pool of PCR products that were then analyzed by NGS. The primers to produce the NGS library contain Junior454-specific sequences. MID, multiple identifier: MID1, identifier for RACE products from normal human testis; MID2, identifier for RACE products from TSA-treated testicular cancer cells. (b) The Venn diagram shows the overlap of genes identified by RACE and NGS from testis and from TSAtreated testicular cancer cells, as well as TSA-induced genes (fold change, FC $>5$ ) determined using array analyses (Figure 1a). The FC of expression (array hybridization) and the numbers of NGS reads for each candidate gene are listed in Table 1 and the NGS raw data is shown in Supplementary Table S5. While ERV9-LTR transcripts from 433 genes were identified in normal testes, only 150 LTR transcripts were detected in TSA-treated testicular cancer cells. Eighteen TSA-inducible genes harbor ERV9-LTR-derived transcripts and were identified by RACE-NGS, both in testes and in testicular tumor cells. While the tumor suppressor TP63 was previously shown to contain an upstream LTR promoter driving GTAp63 expression in testicular germ cells, ${ }^{1}$ an ERV9-LTR-driven transcript was also found to arise from the proapoptotic TNFRSF10B gene and this was chosen for subsequent functional analysis. (c) Interaction network of candidate genes involved in cell signaling. A gene ontology search of the 18 candidate genes (of Figure 2b) identified nine of these genes (red circles) having a role in intracellular signaling pathways. The PROTEOME software generated an interaction network based on PubMedindexed literature, with genes depicted as circles and interaction between different genes as arrows. Green arrows indicate transactivation of the target gene or activation of the target protein, while black arrows mark other kinds of interactions, e.g., protein binding. Gene products within the network function in apoptosis, directly or indirectly, as exemplified by the $\mathrm{p} 53$ family of proteins or the tumor necrosis factor (TNF) superfamily 
(Figure 2b; Supplementary Tables S3 and S5). Analysis of the exact TNFRSF1OB transcripts that originate from the ERV9-LTR showed that these transcripts comprise the protein-coding portion of the TNFRSF1OB gene, representing translatable mRNAs (Figure $3 a$ and
Supplementary Figure S3). Thus ERV9-LTR-driven transcripts of the TNFRSF1OB gene contain the sequences encoding the death receptor DR5.

Expression analysis of TNFRSF1OB in a variety of human tissues revealed the expected, ubiquitous pattern of the total

a

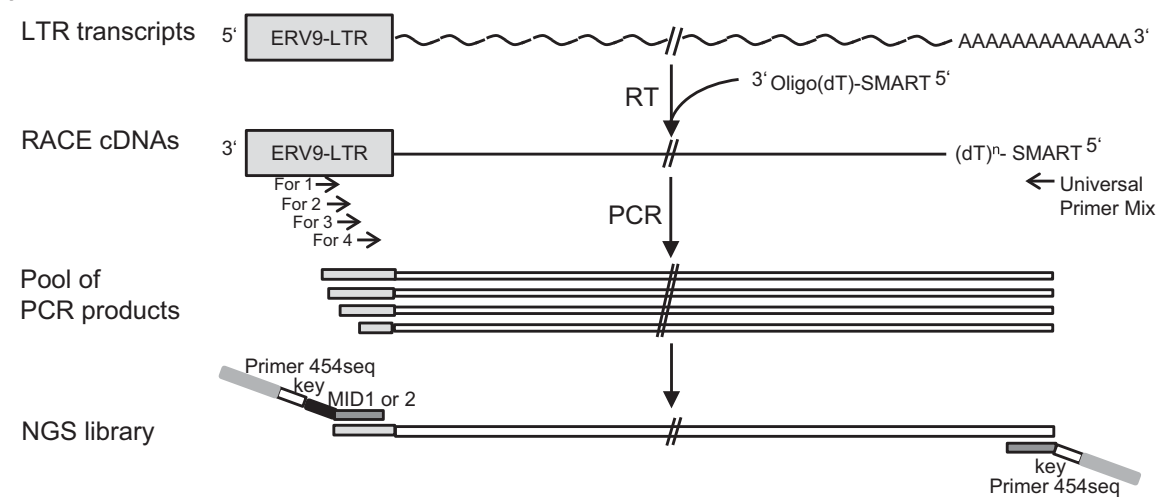

b

\begin{tabular}{|c|c|c|c|}
\hline $\begin{array}{l}\text { NGS_MID2 - } \\
\text { testicular cancer + TSA }\end{array}$ & \multicolumn{3}{|c|}{$\begin{array}{l}\text { Genes with ERV9-LTR transcripts that are } \\
\text { differentially expressed upon TSA (array FC>5) }\end{array}$} \\
\hline 95 & ACSBG1 & CPED1 & C9orf53 \\
\hline & C9orf85 & CCR4 & CSF3 \\
\hline & IER3 & KCNN3 & LINC01194 \\
\hline & NR1H4 & PIK3C2G & PTPN13 \\
\hline 1369 & RADIL & SLC36A2 & TENM1 \\
\hline Microarray FC & $T M O D 1$ & TNFRSF10B & TP63 \\
\hline
\end{tabular}

C

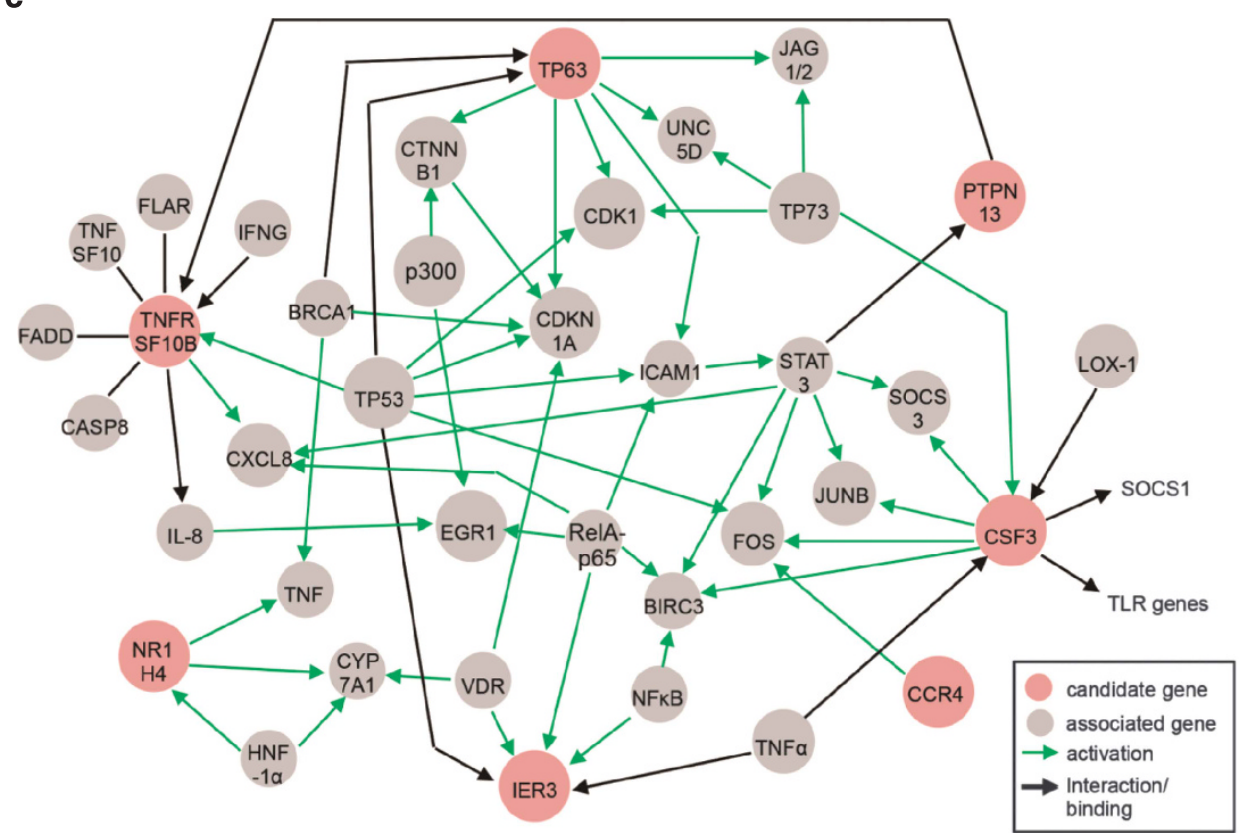


amount of all protein-coding transcripts. However, for the LTRdriven transcripts, the highest expression was found in testes (Figure 3b), as we had reported previously for GTAp63. ${ }^{3}$ Thus, although TNFRSF1OB expression was also high in small intestine, its ERV9-LTR-driven transcripts are specifically found in testicular tissue.

As previously shown, in comparison with normal human testis, testicular cancer cells have lost ERV9-LTR-driven expression of GTAp63, and GTAp63 expression could be restored upon treatment with $\mathrm{TSA}^{3}$ To address whether HDAC sensitivity is specific for LTR promoters of the ERV9 subfamily, we quantified mRNA expression of known human ERV9-LTRregulated genes, including TNFRSF10B, in GH testicular cancer cells that were treated with increasing concentrations of the HDACis TSA and SAHA. mRNA level of all analyzed LTR-driven transcripts were significantly upregulated upon HDAC inhibition (Figure 3c). In contrast, HDACi treatment did not induce transcription from retroviral promoters of other HERV subfamilies.

The insertion of the ERV9-LTR upstream of TNFRSF10B occurred 18 million years ago, at the beginning of Hominid evolution. The spread of ERV9 through the genome occurred fairly recently, in a period when higher primates were arising. ${ }^{27}$ In the case of GTAp63, we had previously raised the hypothesis that LTR insertion occurred concomitantly with the development of hominids, perhaps facilitating the maintenance of their genome in the male germline. ${ }^{3}$ Here, we tested at which evolutionary stage the insertion of the LTR upstream of TNFRSF10B occurred. PCR analysis of the DNA from several primates (Figure 4a) as well as a BLAST search on the available primate genomes and consensus sequences of ERV9 subfamilies (Supplementary Figure S4) and comparison with the known evolutionary tree (Figure $4 b$ ) revealed that this insertion occurred roughly 18 million years ago, when Hominoids diverged from other primates. This time of insertion is only one stage earlier than for GTAp63, raising the possibility that each insertion enabled a more stringent control of germline integrity than before.

Human testis but not testicular cancer contains readily detectable levels of the TNFRSF10B gene product DR5. As the ERV9-LTR-driven product of TP63 GTAp63 is found in human testes but not in testicular cancer, ${ }^{3}$ we addressed whether this is also true for the product of the TNFRSF10B gene, DR5. Immunohistochemistry analyses, retrieved from the Human Protein Atlas, indicated strong DR5 expression in human testis throughout the seminiferous duct (Supplementary Table S6), and this is in accordance with the previously published tissue distribution of DR5 in humans. ${ }^{28}$ In contrast, the detectable levels of DR5 in testicular cancers, were much lower or entirely absent. This suggests that during the formation of testicular cancer, ERV9-LTR-driven gene expression is silenced not only in the case of GTAp63, but also of TNFRSF10B.

LTR-driven TNFRSF10B expression enables apoptosis of testicular cancer cells upon treatment with HDACis. The general importance of DR5 and its ligand TRAIL in HDACimediated cell death has been noted previously, ${ }^{29,30-32}$ albeit 
without the context of endogenous retroviral LTRs and their regulatory activities. We addressed whether HDACis induce TNFRSF10B expression in testicular cancer cells and whether this mediates apoptosis. As expected, treatment of $\mathrm{GH}$ cells with TSA led to strong enhancement of the LTRdriven TNFRSF10B transcripts, as revealed by quantitative RT-PCR (Figure 5a). While total TNFRSF10B mRNA was increased $\sim 10$-fold, the LTR-driven transcripts were induced several hundred fold. A similar induction of the TNFRSF10B LTR transcripts was seen in other testicular cell lines (NCCIT, Susa, 1618-K) upon HDAC inhibition (Figures $5 \mathrm{~b}$ and $\mathrm{c}$ ), while total TNFRSF10B mRNA levels were increased $\sim 10-$ 20-fold in these cells (Supplementary Figure S5A). Treatment of testicular cancer cells with the clinically used HDACi SAHA had a similar effect on LTR-driven TNFRSF1OB transcription (Figure $5 \mathrm{c}$ ). In contrast, transcription of the TNFRSF10A gene, that encodes the death receptor DR4 and, according to the Repbase CENSOR tool (http://www.girinst.org/censor/), ${ }^{33}$ has no ERV9-LTR within its genomic region, was not increased in $\mathrm{GH}$ cells upon TSA treatment (Supplementary Figure S5B). As enhanced surface expression of DR5 upon p53 activation by Nutlin 3a was recently shown, we tested how this compound affects the different transcripts of TNFRSF10B. In contrast to the strong induction of the LTR transcripts by TSA, Nutlin $3 a$ treatment only resulted in a moderate induction of overall TNFRSF10B expression in testicular cell lines (Supplementary Figure S5C), as expected, ${ }^{34}$ but did not induce the LTR-driven transcripts. The p53-responsive element within TNFRSF10B was previously mapped to intron 1 of TNFRSF $10 B,{ }^{35}$ according to the traditional nomenclature. We therefore propose that p53 induces the previously described, non-LTR-driven transcript of TNFRSF10B but not the LTR-dependent transcripts. The RT-PCR assay detects both transcripts, resulting in a moderate increase in total DR5-encoding mRNA upon Nutlin treatment. The strong induction of TNFRSF10B expression from the LTR promoter thus represents a specific response to HDAC inhibition.

Finally, we investigated the contribution of the TNFRSF10B gene to the apoptosis of testicular cancer cells. DR5 protein expression in $\mathrm{GH}$ cells was diminished by transfection of two different siRNAs. To investigate whether DR5 is essential for apoptosis, we stimulated cell death using either TSA (12 h, $500 \mathrm{nM})$ or the DR5 ligand TRAIL (10 h, $50 \mathrm{ng} / \mathrm{ml})$, or a combination of both. Knockdown efficiencies are shown in Supplementary Figure S5D. Cells transfected with control siRNA survived poorly when treated with the combination, as detected by measuring cell confluency at diverse time points after treatment. The combination of TSA with TRAIL reduced clonogenic survival to a greater extent than either compound alone. In contrast, specific depletion of DR5 attenuated death induction and allowed long-term cell survival (Figure 5d,Supplementary Figure S5E). This was also observed by western blot analysis of PARP-1 and caspase 3 cleavage, indicators of apoptosis (Figure $5 e$, Supplementary Figure S5F). Treatment of GH cells with TSA and TRAIL resulted in nearly complete cleavage of PARP-1 in control-transfected cells. Importantly, cell survival was rescued by depletion of DR5. Moreover, combined treatment of testicular cells with TSA and TRAIL had a synergistic effect on cell viability (Supplementary Figure S5G). Hence, apoptotic death of testicular cancer cells is efficiently induced by HDAC inhibition, in combination with a death ligand.

The drug cDDP is the mainstay of current testicular cancer therapy, nevertheless not all patients are cured, and tumor cell resistance is not uncommon. ${ }^{36}$ Moreover, cDDP displays considerable toxicities (such as nausea, infertility and hearing loss). ${ }^{37-39}$ Therefore, we addressed whether combined treatment of HDACi and cDDP could cooperate to enhance testicular cancer cell death. Testicular cancer cells were treated with HDACi alone, or in combination with cDDP, and cell viability was quantified (Figure 5f; Supplementary Table S7). In all tested cells, combined treatment of HDACi and cDDP enhanced cell death as compared with cDDP treatment alone. Notably, for the combination of $100 \mathrm{nM}$ TSA and cDDP, the Non-Constant Combination Index $(\mathrm{Cl})$, calculated as previously described, ${ }^{40}$ went down to $0.5-0.7$, indicating a robust synergistic effect of combined treatment with HDACi and cDDP on testicular cancer cell death. This synergism might be used to clinically improve testicular cancer treatment.

\section{Discussion}

Our results strongly suggest that Hominoids use the ERV9LTR to drive a broad range of genes, mostly in the male germline. At least some of these genes enhance the apoptotic potential of germline cells, strongly suggesting that ERV9-LTR enhances the rigidity of surveillance by pushing damaged germ cells readily into apoptosis. Together, ERV9-LTR-driven genes thus confer a guardian function for the germline of male Hominoids.

Not all identified ERV9-LTR-induced genes are known to directly induce cell death. Their functions in the context of the male germline may indirectly contribute to proper reaction in the face of damage. For instance, IRGM, a member of the p47 immunity-related GTPases family, is a mediator of autophagy as part of a defense mechanism that acts on intracellular pathogens, ${ }^{41,42}$ but is also involved in Crohn's disease, ${ }^{43,44}$ a chronic inflammatory bowel disease. We propose that ERV9-LTR-mediated IRGM expression may also enhance the defense mechanisms of germ cells against intracellular pathogens and/or contributes to the regulation of inflammatory responses in the testes. Another immune modulator is the immediate early response protein IER3, being associated with inflammatory stress and inflammatory diseases. ${ }^{45,46}$ In addition, it is conserved in rodents and humans, where it enhances apoptosis upon DNA damage, p53 activation or diverse stimuli such as TNFa, TRAIL or irradiation. ${ }^{47}$ IER3-deficient mice exert increased genomic instability due to sustained DNA lesions. ${ }^{48}$

Similar functions in inflammation and/or cell death may apply to additional ERV9-LTR-driven genes, such as CCR4, NR1H4 and PTPN13. In gastric cancer, TNFa leads to aberrant chemokine receptor CCR4 expression, which then suppresses immune reactions against the cancer cells, a phenomenon known as tumor-induced immunosuppression. ${ }^{49}$ The transcription factor $\mathrm{NR} 1 \mathrm{H} 4$ protects gastric cells against inflammation-induced DNA damage. ${ }^{50}$ 
The Fas-associated phosphatase PTPN13 inhibits the expression of Fas at the cell surface, thereby regulating apoptotic signaling. Its expression has been also linked to testicular germ cell apoptosis in mammals, during spermatogenesis and also after treatment with Mono-(2-ethylhexyl) phthalate (MEHP). MEHP induces an increase in PTPN13 expression, and concomitant massive germ cell death. ${ }^{51}$ In humans, PTPN13 expression is also necessary for DNA damageinduced apoptosis of prostate cancer cells. ${ }^{52}$
Endogenous retroviruses are generally regarded as 'selfish' genetic elements that spread throughout the genome during evolution much like an infectious disease. Consistently, there were 'outbreaks' of ERV9 mobilization during recent primate evolution. ${ }^{6,27,53}$ Nonetheless, we propose that at least a subset of ERV9 insertions were beneficial for the host, allowing enhanced germline protection in the face of prolonged lifetime and fertility of male individuals, as compared with more ancient primates. The work presented here suggests that this

a

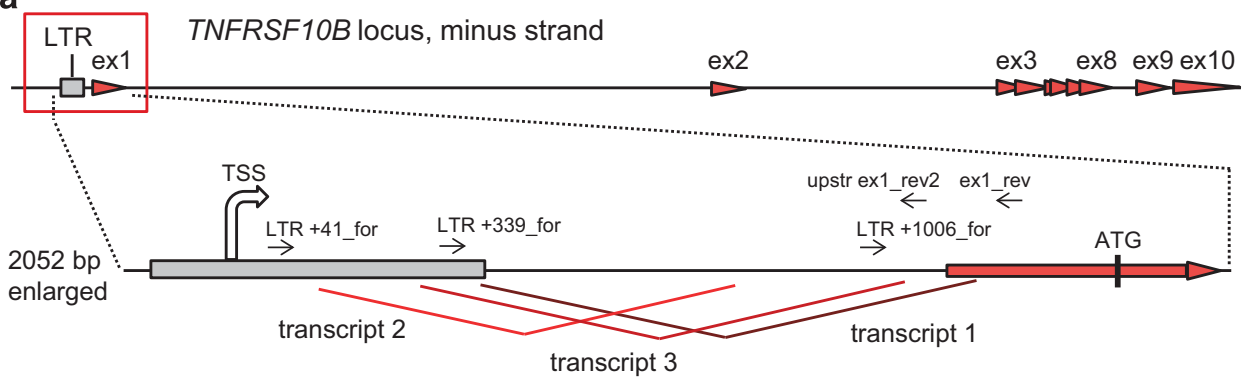

b
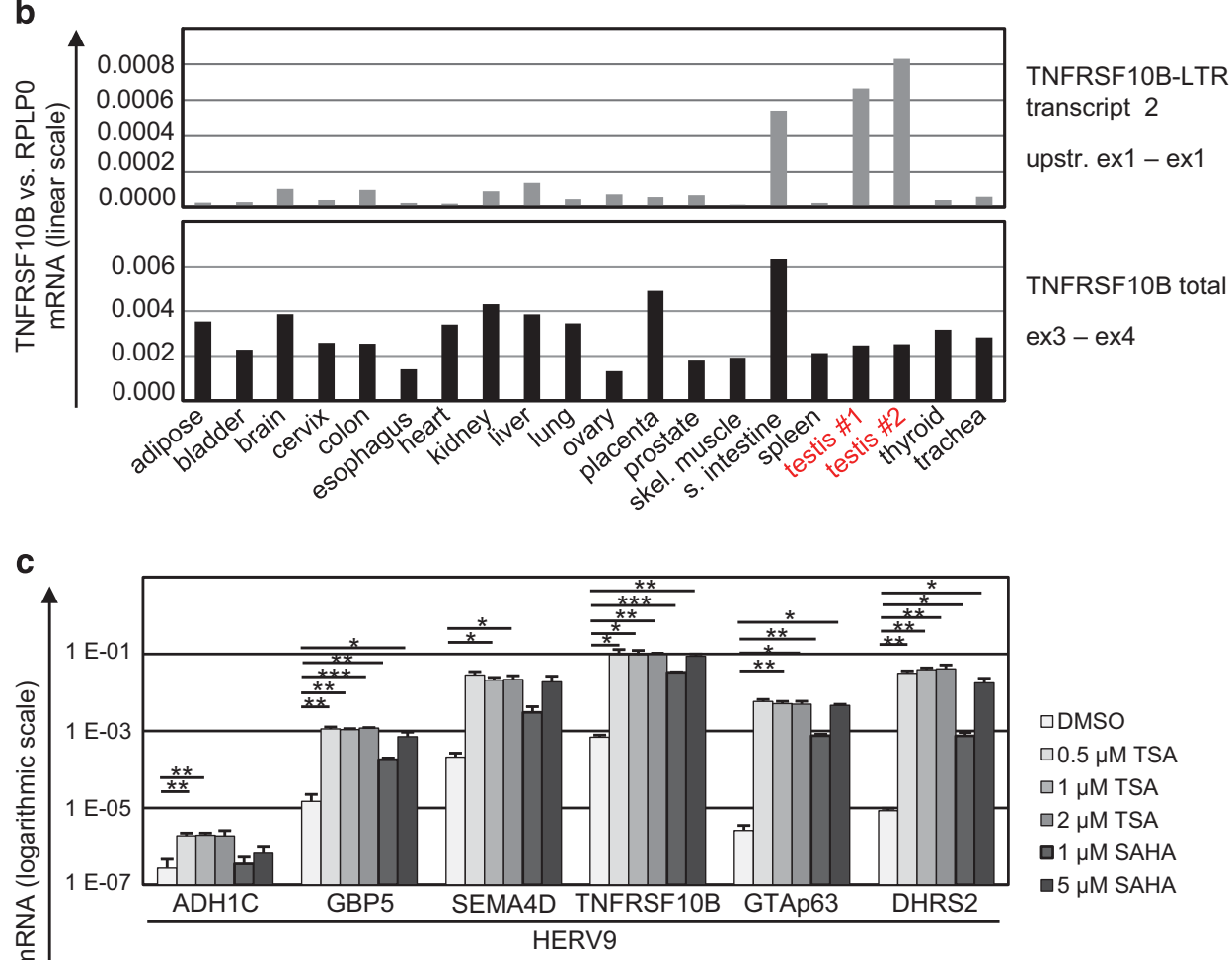

口DMSO

$\square 0.5 \mu \mathrm{M}$ TSA

$\square 1 \mu \mathrm{M}$ TSA

$\square 2 \mu \mathrm{M}$ TSA

$\square 1 \mu M$ SAHA

$\square 5$ MM SAHA 
association of ERV9 with such surveillance genes has occurred more than once, perhaps representing a prerequisite for human evolution. The importance of other primate-specific endogenous retroviral elements has been recently shown, reporting that
HERV-H-regulated transcription is essential for the self-renewal of human pluripotent stem cells. ${ }^{54}$

From the evolutionary perspective of an endogenous retrovirus, it is sensible to display activity in germline cells,

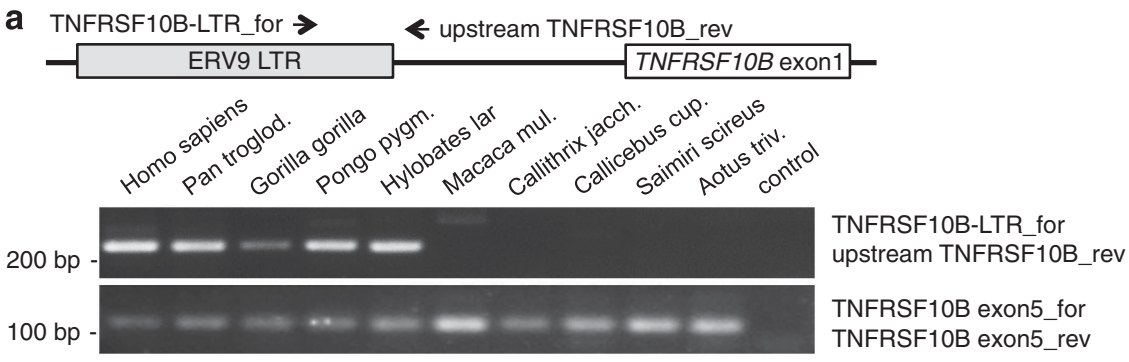

b Insertion of ERV9-LTR (subfamily IX)

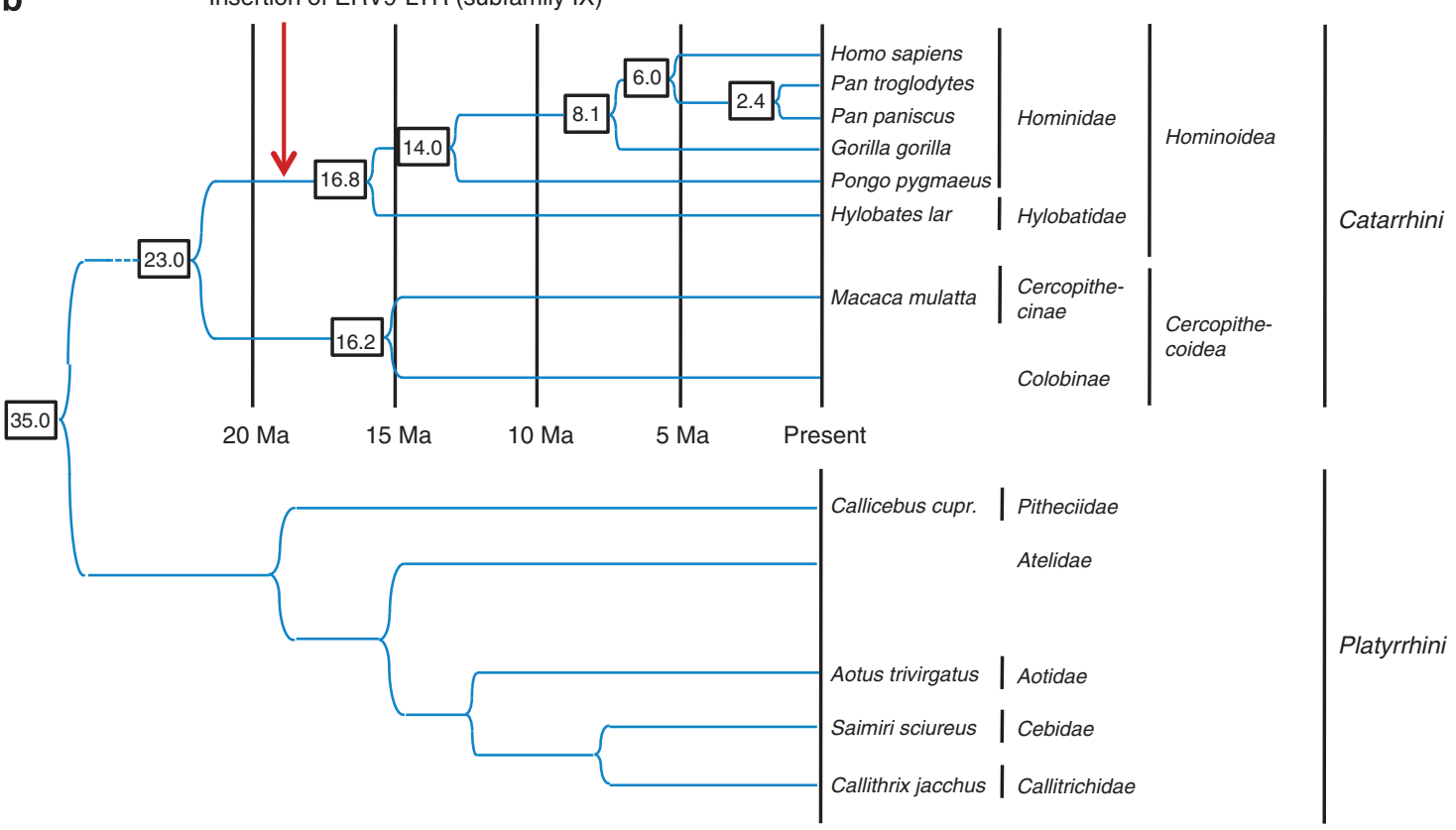

Figure 4 Insertion of the ERV9-LTR adjacent to TNFRSF10B in hominoid primates. (a) PCR amplification of the region comprising the ERV9-LTR and TNFRSF10B exon 1 sequences from genomic DNA of primates, yielding a specific product in Hominidae and Hylobatidae but not in other primates. Binding of the primers 'TNFRSF10B LTR_for' and 'upstream TNFRSF10B_rev' is shown in the upper scheme; sequences are given in Supplementary Table S4. In contrast, a portion of the TNFRSF10B gene was amplified from all primates. (b) Timing of primate evolution and ERV9-LTR insertion adjacent to TNFRSF10B. The pattern and sequence of the TNFRSF10B-associated ERV9-LTR in primate genomes indicates that the insertion of the ERV9-LTR upstream of TNFRSF10B occurred in the ancestor of Hominoidea, during the time prior to Hominidae separation from Hylobatidae, roughly 18 million years ago ${ }^{2}$

Figure 3 Expression of the death receptor gene TNFRSF10B, encoding Killer/DR5, from an upstream ERV9-LTR. (a) Architecture of the human TNFRSF10B gene, including 10 exons (red arrowheads). The newly identified ERV9-LTR (grey box) is located upstream of the previously described promoter. The region surrounding the LTR and TNFRSF10B exon 1 is shown with a zoom, depicting three different transcripts that are generated from the LTR promoter and alternatively spliced (red lines). The start site of LTR transcription (TSS) is shown by a large arrow, primers for amplification of distinct TNFRSF10B LTR transcripts are indicated by small arrows. Expression of the known and the three newly identified transcripts all result in the synthesis of the same protein, using the start codon located within exon 1. (b) Quantification of TNFRSF10B mRNA expression in a panel of normal human tissues. Real-time RT-PCR was performed using primers that either bind to the region between the LTR and exon 1 (LTR transcript 2; upper panel), or to exons 3 and 4 (total TNFRSF10B mRNA; lower panel). TNFRSF10B mRNA levels were normalized to RPLPO. While similar levels of total TNFRSF10B mRNA were detected in all tissues, the LTR-driven transcript was mainly detected in two different samples of testicular tissue, and in the small intestine. Oligonucleotide sequences are given in Supplementary Table S4. (c) Induction of HERV-regulated transcription upon HDAC inhibition in GH testicular cancer cells is specific for LTRs belonging to the HERV-9 subfamily. Total RNA was isolated from GH cells treated with the solvent DMSO or increasing concentrations of the HDACis TSA or SAHA. Expression of mRNA levels of diverse HERV promoter-driven genes was quantified by real-time RT-PCR, normalized to RPLPO. HDAC inhibition significantly induced the transcription of six HERV-9 LTR-associated genes (upper panel). In contrast, transcription of genes driven by LTRs of the HERV-E, HERV-H or HERV-K subfamilies was rather downregulated upon HDAC inhibition (lower panel). Mean expression ratios of three independent experiments. $P$-values were calculated using Student's $t$-test (ns: $P>0.05,{ }^{*} P<0.05,{ }^{* \star} P<0.01,{ }^{* \star *} P<0.001$ ). Note the logarithmic scale 

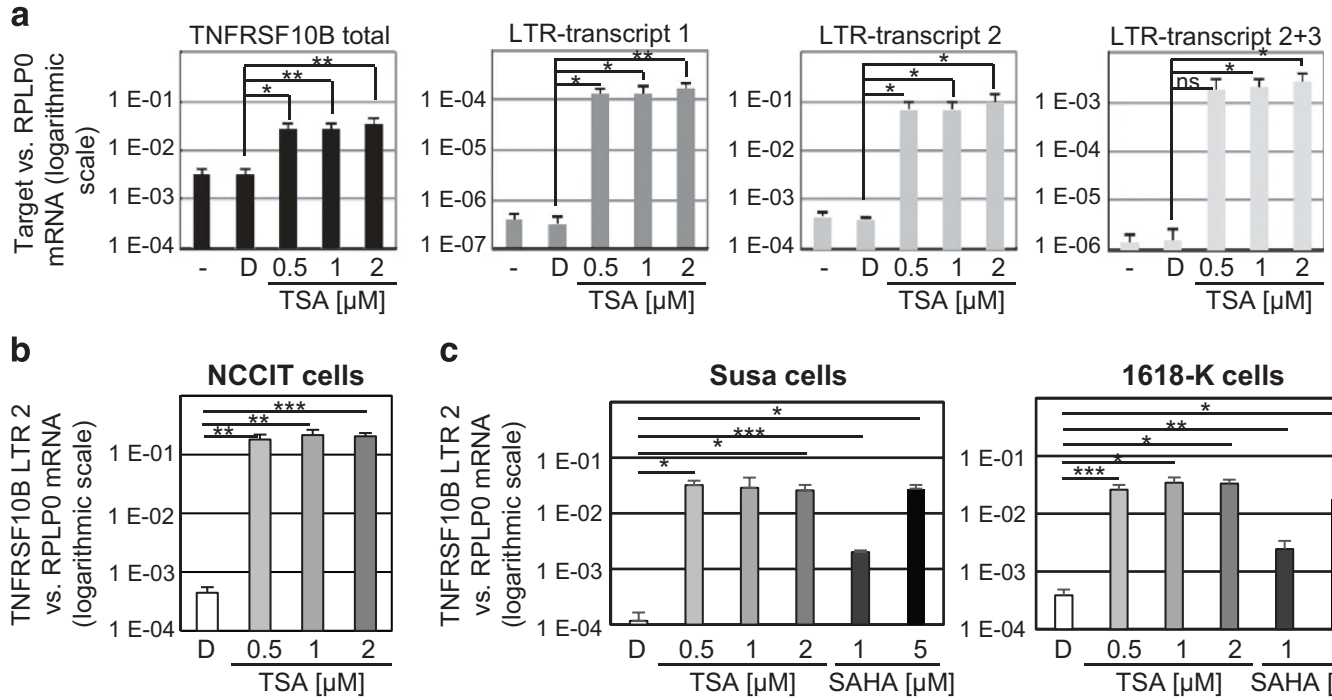

C
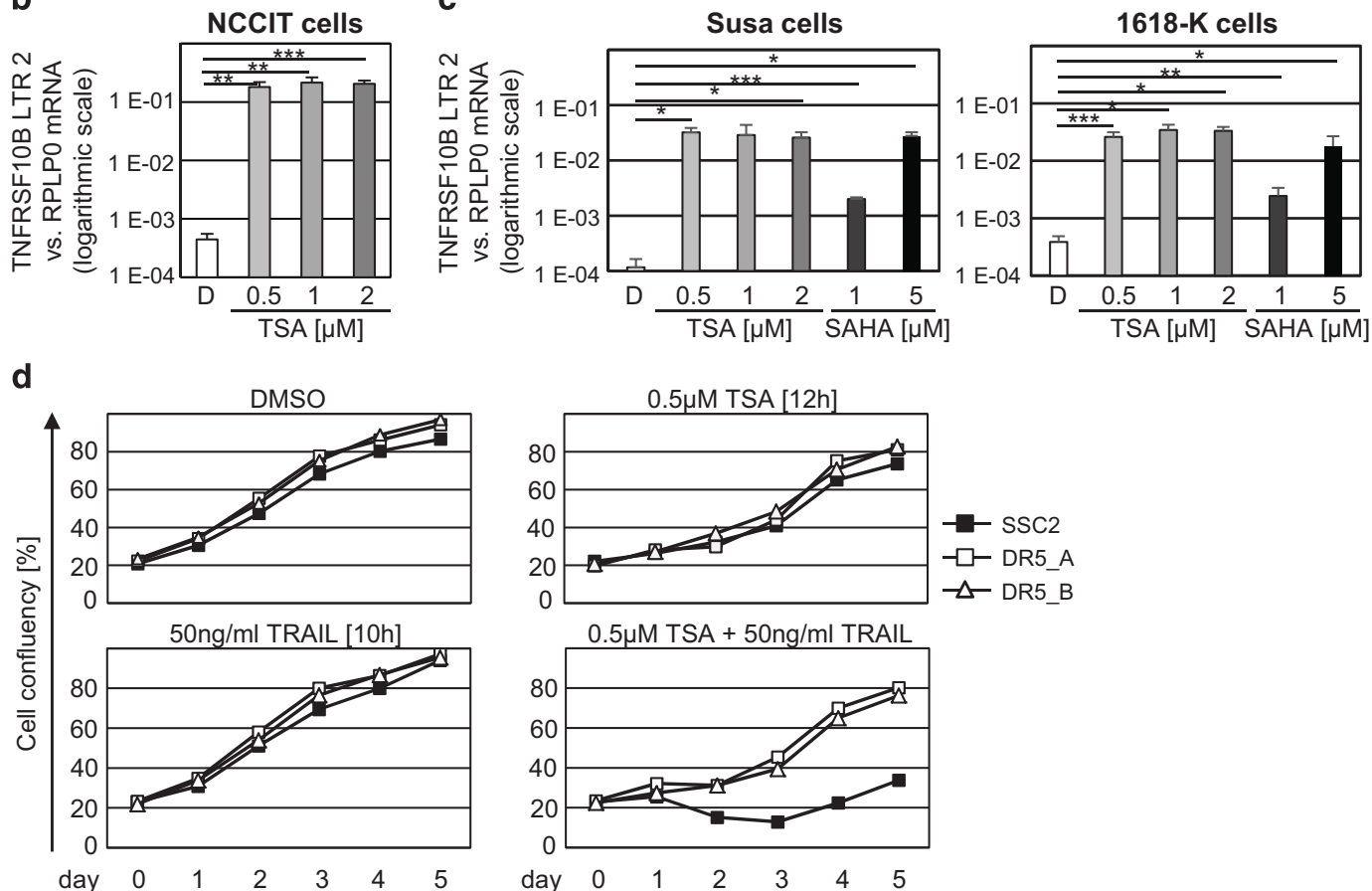

e

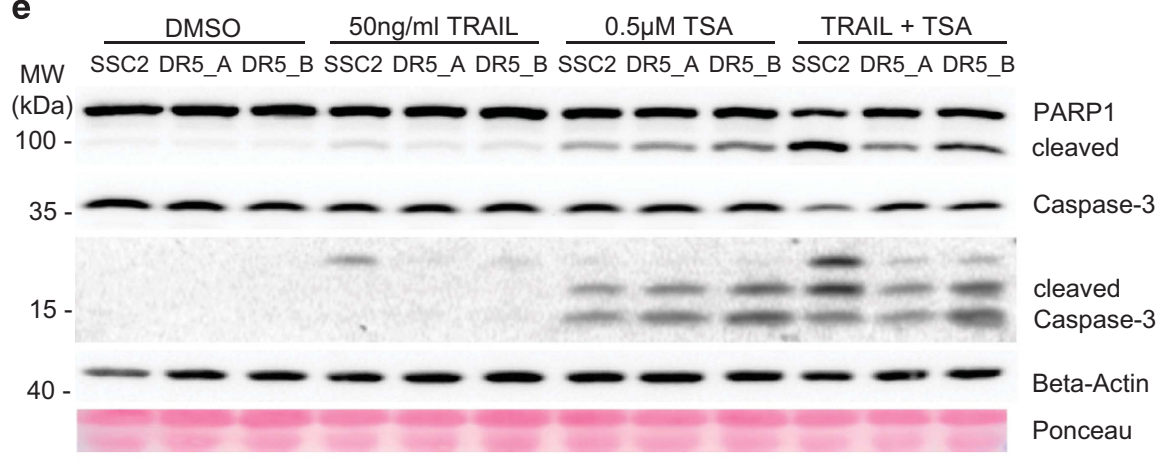

f

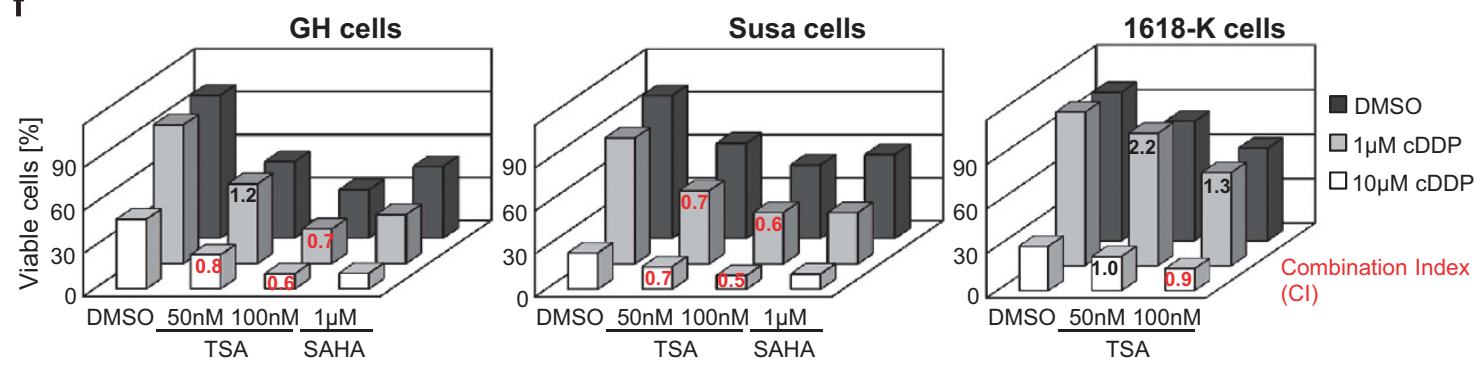


as only these cells will be passed on to the next generation and thereby perpetuate a successful virus re-insertion. Consistently, the ERV9-LTR shows germline-specific promoter activity even in zebrafish, as shown by a transgene where this LTR drives the expression of a green fluorescent protein reporter. $^{55}$ The mechanisms that lead to testis-specific expression appear to involve the transcription factors NF-Y and $\mathrm{Sp} 1,{ }^{56}$ but may also be governed by the expression of antisense transcripts. ${ }^{57}$ In any case, the virus appears to take advantage of ancient mechanisms for testicular transcription, to push the expression of its own genome, but also to re-assort this promoter activity with novel cellular genes.

Our study shows that an ERV9-LTR stimulates the synthesis of the death receptor 5 from the TNFRSF10B gene in testicular cancer cells. Ablation of TNRSF1OB expression by RNA interference impairs apoptosis upon TRAIL addition, indicating that TRAIL-induced apoptosis in testicular cancer cells largely relies on DR5 expression. Moreover, ligand-independent death via DR5 has been observed upon endoplasmic reticulum $(E R)$ stress, where unfolded protein response mediator CHOP increases transcription of TNFRSF10B, leading to apoptosis via caspse-8 activation. ${ }^{58}$ Thus, depending on the context, LTR-driven expression of TNRFSF10B may even contribute to apoptotic susceptibility in the absence of a ligand.

TNFRSF1OB is not only regulated through the upstream ERV9-LTR. Rather, this gene was one of the first to be identified as p53-responsive, and DNA damage induces TNFRSF10B (termed KILLER/DR5 by then) in a p53dependent manner. ${ }^{34}$ The induction of DR5/TRAIL-R2 as a response to DNA damage is not limited to primates but has been observed in rodents as well. Importantly, even in rodents, DR5 is a major determinant of germ cell death upon DNA damage to testes. ${ }^{59,60}$ This argues that the inducibility by p53 is the evolutionary older mechanism to enhance DR5 levels in testes. Only later, when Hominoids evolved, the insertion of the ERV9-LTR added an even more efficient mechanism to keep up the levels of DR5 in the male germline, thereby enhancing genomic surveillance in these cells.

Testicular cancer cells are capable of silencing ERV9-LTR promoter activity, and this abolishes several tumorsuppressive mechanisms. However, the use of HDACis overcomes this phenomenon and may thus represent a viable approach to sensitize testicular cancer cells. Of note, these cancers are already amenable to platinum-based chemotherapy with a high success rate. ${ }^{61}$ Nevertheless, $20 \%$ of patients with metastatic disease cannot be cured, ${ }^{62}$ and cDDP displays severe toxicities, for example, neurotoxicity. ${ }^{37-39}$ This work indicates that HDACi and CDDP synergistically induce cell death in several testicular cancer-derived cell lines (GH, Susa, $1618-K)$. This raises the perspective of clinically using HDACis on testicular cancers that do not respond sufficiently to current standard therapeutic regimens. The HDACi SAHA (Valproat) is FDA-approved, albeit for treating cutaneous T-cell lymphoma, ${ }^{63}$ and this drug also induced ERV9-LTR-driven transcription $^{3}$ and cooperated with cDDP to induce cancer cell death. Although we do not propose changing the current firstline therapy, HDACis may restore a tumor-suppressive mechanism that acts on a range of genes and thus could sensitize initially non-responding testicular cancers. ${ }^{64}$

\section{Materials and methods \\ Cell culture. GH cells were maintained in Dulbecco's Modified Eagle medium supplemented with 10\% FBS. TSA (dissolved in DMSO) was added as indicated, with corresponding amounts of DMSO alone added to controls. In experiments involving siRNA transfection and drug treatment, cells were first reversely transfected using Lipofectamine 2000 (Life Technologies, Darmstadt, Germany), incubated for 36 or $38 \mathrm{~h}$, and then treated with either TSA and/or TRAIL for 12 or $10 \mathrm{~h}$, respectively. Cells were transfected with siRNAs specifically targeting the TNFRSF10B gene, DR5_A or DR5_B, or with the scrambled control siRNA SSC2 (all Ambion, Darmstadt, Germany) at a final concentration of $30 \mathrm{nM}$.}

Array hybridization. Total RNA isolated from cells using TRIzol reagent (Life Technologies) were processed using the Low RNA Input Linear Amplification Kit Plus (Agilent, Waldbronn, Germany). Samples were hybridized in duplicates on Agilent Human $4 x 44 \mathrm{~K}$ arrays. Cy3 intensities were then detected using the Agilent DNA microarray scanner at 5 micron resolution. Differential gene expression was

\footnotetext{
Figure 5 TNFRSF10B expression contributes to apoptosis of testicular cancer cells upon HDAC inhibition. (a) HDAC inhibition increases the expression of TNFRSF10B from the LTR promoter, as detected by quantitative real-time RT-PCR. Total RNA was isolated from GH cells treated for $18 \mathrm{~h}$ with the indicated concentrations of TSA or DMSO as control. CDNAs were amplified with primers corresponding to total TNFSRF10B or the three distinct LTR transcripts. Mean values, normalized to RPLPO, and standard deviations from three independent experiments are shown. $P$-values were calculated using Student's $t$-test (ns: $P>0.05,{ }^{\star} P<0.05,{ }^{* \star} P<0.01$, ${ }^{\star * \star} P<0.001$ ). Notably, the relative level of LTR-derived mRNAs are upregulated by several 100-fold upon TSA treatment (logarithmic scale). (b) Strong induction of the TNFRSF10B transcription from the LTR promoter was also seen upon TSA treatment of NCCIT testicular cancer cells, as determined by quantification of the TNFRSF10B LTR transcript 2 mRNA level. (c) TNFRSF10B expression from the LTR promoter was also increased upon treatment of testicular cancer cells with the HDACi SAHA, a clinically used chemotherapeutic drug. Susa or 1618-K testicular cancer cells were treated with increasing concentrations of TSA or SAHA, or the solvent DMSO. Quantification of TNFRSF10B LTR transcript 2 expression by real-time RT-PCR, normalized to RPLPO. Notably, SAHA treatment had a similar effect on LTR-driven transcription as compared with TSA treatment (logarithmic scale). (d) Depletion of DR5 diminished TSA- and TRAIL-induced apoptosis in testicular cancer cells. After transfection of GH cells with siRNAs targeting DR5 or the control scrambled siRNA SSC2, cells were treated with TSA, or the DR5 ligand TRAIL, or a combination of both. Treatment was performed for $12 \mathrm{~h}$ (TSA) or $10 \mathrm{~h}$ (TRAIL), washed out at day 1 , and cell survival upon treatment was assessed by monitoring of cell confluency consecutively for 4 days. A representative result of three independent experiments is shown; the results of the other two experiments are displayed in Supplementary Figure S5E. Only the combination of TSA and TRAIL led to strongly suppressed cell survival, and this was rescued specifically by the knockdown of DR5. (e) Immunoblot analysis of cells transfected and treated with TRAIL and/or TSA, as described in the legend to Figure 5d. Apoptosis was determined by staining PARP1 and cleaved caspase 3. Beta-actin and Ponceau staining served as controls. In comparison with single treatments, the combined treatment with TRAIL and TSA markedly enhanced PARP1 and caspase 3 cleavage. This effect was rescued in DR5-depleted cells. (f) Synergistic effect of combined treatment of testicular cancer cells with the HDACi TSA and cDDP; the latter drug represents the mainstay of current therapy to eliminate testicular cancer. Testicular cancer cells were treated with the solvent DMSO or increasing concentrations of TSA and/or the indicated concentrations of CDDP. Cell viability was determined $24 \mathrm{~h}$ post treatment by luminometric ATP quantification. Mean values of three independent experiments are shown. For each sample treated with the combination of TSA and CDDP, the Non-Constant Combination Index (Cl) was calculated. ${ }^{41}$ Notably, in all cell lines, treatment with TSA synergistically enhanced cell death induced by cDDP treatment (mean $\mathrm{Cl}$ values indicated in red). $\mathrm{Cl}<1$ : synergism; $\mathrm{Cl}=1$ : additive effect; $\mathrm{Cl}>1$ : antagonism
} 
assessed using ANOVA modeling, non-linear local regression normalization and component wise t-tests.

3' RACE was performed using the SMART RACE Kit (Clontech, Takara Bio, SaintGermain-en-Laye, France). In brief, 3'RACE cDNA was generated from normal human testicular RNA (Life Technologies) or mRNA isolated from TSA-induced GH cells using the modified oligo-dT primer provided within the kit. cDNAs with the SMART oligo sequence at their 3' end were amplified with different ERV9-LTR specific forward primers (Supplementary Table S4) and the Universal Primer Mix (Clontech) as reverse primer.

GSJunior 454 next-generation sequencing. Each purified RACE product was reamplified with forward primers binding to the 3' portion of the ERV9-LTR (Supplementary Table S4) and a nested reverse primer using the Advantage2 PCR kit (Takara Bio). The GSJunior 454 library was prepared pooling purified reamplified RACE products to equimolar amounts using the Lib-L library preparation kit (Roche, Mannheim, Germany). One-way sequencing was then performed on the GSJunior 454 instrument (Roche).

Quantitative mRNA analysis by qRT-PCR. Total RNA was isolated using TRIzol (Life Technologies), followed by reverse transcription with Moloney Murine Leukemia Virus reverse transcriptase (NEB, Frankfurt Main, Germany) and a mixture of oligo(dT) and random nonamer primers. A SYBR Green master mix including Taq polymerase (Primetech ALC, Minsk, Belarus) was used for real-time PCR. The primer sequences are shown in Supplementary Table S4. PCR conditions were as follows: initial denaturation $2 \mathrm{~min}$ at $95^{\circ} \mathrm{C}$, followed by 40 cycles of $95^{\circ} \mathrm{C}$ for $15 \mathrm{~s}$ and $60^{\circ} \mathrm{C}$ for $60 \mathrm{~s}$. Gene expression levels were normalized to RPLPO as reference gene and calculated using the $2^{-\Delta \Delta C t}$ method.

Amplification of genomic DNA. Genomic DNA isolated from human cells or diverse ape species was PCR-amplified with Taq polymerase (Fermentas, Thermo Scientific, Schwerte, Germany; initial denaturation 3 min at $95^{\circ} \mathrm{C}, 32$ cycles of $20 \mathrm{~s}$ at $95^{\circ} \mathrm{C}, 25 \mathrm{~s}$ at $58^{\circ} \mathrm{C}$ and $25 \mathrm{~s}$ at $72{ }^{\circ} \mathrm{C}$, followed by $5 \mathrm{~min}$ at $72{ }^{\circ} \mathrm{C}$ ). PCR products were analyzed by agarose gel electrophoresis. Primer sequences were as follows: TNFRSF10B LTR_for 5'-GAACATCAGAAGGAACAAACTCC-3', Upstream TNFRSF10B_rev 5'-GTGTCCCTGCACCNTTGCTAC-3'; TNFRSF10B exon5_for 5'-GTACNCCCTGGAGTGACATC-3', TNFRSF10B exon5_rev 5'-ATGATGATGC CTGAGANNG-3'.

Immunoblot analyses. Total protein was isolated by scraping the cells directly in $5 x$ diluted Laemmli sample buffer $(0.35 \mathrm{M}$ Tris, pH 6.8, 30\% Glycerin, $10 \%$ SDS, $9.3 \%$ DTT, $0.02 \%$ Bromphenol blue), sonication for $5 \mathrm{~min}$ and boiling at $95^{\circ} \mathrm{C}$ for $5 \mathrm{~min}$. After separation by SDS-PAGE, proteins were transferred to nitrocellulose, followed by overnight incubation with antibodies diluted in PBS containing $5 \%$ dried milk and $0.1 \%$ Tween 20 . Antibodies were rabbit anti-PARP (9542; Cell Signaling, New England Biolabs, Frankfurt Main, Germany, 1:1000), rabbit anti-caspase-3 (9662; Cell Signaling, 1:500), rabbit anti-cleaved caspase-3 (9661 S, Cell Signaling, 1:500) and mouse anti-beta-actin (ab6225; Abcam, Cambridge, UK, 1:15,000). Primary antibodies were detected by peroxidasecoupled secondary antibodies (Jackson Immunoresearch, Newmarket, UK) and chemiluminescence (Pierce, Thermo Scientific).

Clonogenic cell survival. GH cells $\left(1.3 \times 10^{5}\right)$ were reversely transfected with either $30 \mathrm{nM}$ control siRNA SSC2 or $15 \mathrm{nM}$ DR5_A or DR5_B, filled up with $15 \mathrm{nM}$ SSC2. $24 \mathrm{~h}$ after transfection, the growth medium was changed and cell confluence was assessed using the Celigo cytometer (Cyntellect, San Diego, CA, USA) (first measurement, $t=0$ ). Thirty-six hours after the initial transfection, the cells were treated with TSA and/or TRAIL; $12 \mathrm{~h}$ thereafter, the medium was changed again, and cell confluency was measured for the second time $(t=1)$. Subsequently, the medium was changed every $24 \mathrm{~h}$, followed by cell confluence measurement $(t=2$ to $t=5)$. Experiments were performed three times independently.

ATP-luminometry to measure cell viability. Cells (2000 (GH or Susa) or $27001618-K)$ were seeded per well in 96 -well plates. Forty-eight hours after seeding, the cells were treated with TSA $(25 \mathrm{nM}, 50 \mathrm{nM}, 100 \mathrm{nM})$ and/or cDDP $(1 \mu \mathrm{M}, 10 \mu \mathrm{M})$ and/or TRAlL $(25 \mathrm{ng} / \mathrm{ml}, 50 \mathrm{ng} / \mathrm{ml})$ for $24 \mathrm{~h}$. All treatments were performed in triplicates. Next, cell viability was determined using the CellTiter-Glo luminescent cell viability assay kit (Promega, Madison, WI, USA), measuring the amounts of ATP in cell lysates in luciferase assays. The luminescence was quantified using a DLReady Centro LB 960 luminometer (Berthold Technologies,
Bad Wildbad, Germany). Experiments were performed three times independently. For each experiment, synergistic drug effects were quantified by calculating the combination index $(\mathrm{Cl})$, as had been previously described by Chou and Talalay, ${ }^{41}$ using the software CompuSyn (ComboSyn, Inc., Paramus, NJ, USA).

\section{Conflict of Interest}

The authors declare no conflict of interest.

Acknowledgements. We thank the members of the Göttingen transcriptome laboratory for expert array analysis. Our work was supported by the Wilhelm Sander Stiftung, the German Cancer Aid / Dr. Mildred Scheel Stiftung, and the German Research Foundation (DFG). S. K. K. was supported by the Göttingen Graduate School of Neurosciences and Molecular Biosciences (GGNB) during this work.

\section{Author contributions}

UB, SKK and MD conceived the project and designed experiments. UB and MD drafted the manuscript. UB and SKK performed and analyzed the experiments. LW helped with the experimental design of the large-scale sequencing experiments. AL analyzed the next-generation sequencing data. All authors read and approved the manuscript.

1. Lander ES, Linton LM, Birren B, Nusbaum C, Zody MC, Baldwin J et al. Initial sequencing and analysis of the human genome. Nature 2001; 409: 860-921.

2. Jern P, Coffin JM. Effects of retroviruses on host genome function. Annu Rev Genet 2008; 42: 709-732.

3. Beyer U, Moll-Rocek J, Moll UM, Dobbelstein M. Endogenous retrovirus drives hitherto unknown proapoptotic p63 isoforms in the male germ line of humans and great apes. Proc Natl Acad Sci USA 2011; 108: 3624-3629.

4. Liu M, Eiden MV. Role of human endogenous retroviral long terminal repeats (LTRs) in maintaining the integrity of the human germ line. Viruses 2011; 3: 901-905.

5. Di Cristofano A, Strazzullo M, Longo L, La Mantia G. Characterization and genomic mapping of the ZNF80 locus: expression of this zinc-finger gene is driven by a solitary LTR of ERV9 endogenous retroviral family. Nucleic Acids Res 1995; 23: 2823-2830.

6. Di Cristofano A, Strazzullo M, Parisi T, La Mantia G. Mobilization of an ERV9 human endogenous retroviral element during primate evolution. Virology 1995; 213 : 271-275.

7. Chen HJ, Carr K, Jerome RE, Edenberg HJ. A retroviral repetitive element confers tissuespecificity to the human alcohol dehydrogenase $1 \mathrm{C}(\mathrm{ADH1C})$ gene. DNA Cell Biol 2002; 21: 793-801.

8. Heinz S, Krause SW, Gabrielli F, Wagner HM, Andreesen R, Rehli M. Genomic organization of the human gene HEP27: alternative promoter usage in HepG2 cells and monocytederived dendritic cells. Genomics 2002; 79: 608-615.

9. Bekpen C, Marques-Bonet T, Alkan C, Antonacci F, Leogrande MB, Ventura M et al. Death and resurrection of the human IRGM gene. PLoS Genet 2009; 5: e1000403.

10. Plant KE, Routledge SJ, Proudfoot NJ. Intergenic transcription in the human beta-globin gene cluster. Mol Cell Biol 2001; 21: 6507-6514.

11. Routledge SJ, Proudfoot NJ. Definition of transcriptional promoters in the human beta globin locus control region. J Mol Biol 2002; 323: 601-611.

12. Long Q, Bengra C, Li C, Kutlar F, Tuan D. A long terminal repeat of the human endogenous retrovirus ERV- 9 is located in the $5^{\prime}$ boundary area of the human beta-globin locus control region. Genomics 1998; 54: 542-555.

13. Strazzullo M, Parisi T, Di Cristofano A, Rocchi M, La Mantia G. Characterization and genomic mapping of chimeric ERV9 endogenous retroviruses-host gene transcripts. Gene 1998; 206: 77-83

14. Ling J, Pi W, Bollag R, Zeng S, Keskintepe M, Saliman $\mathrm{H}$ et al. The solitary long terminal repeats of ERV-9 endogenous retrovirus are conserved during primate evolution and possess enhancer activities in embryonic and hematopoietic cells. $J$ Virol 2002; 76: 2410-2423.

15. Zhao X, Liu X, Su L. Parthenolide induces apoptosis via TNFRSF10B and PMAIP1 pathways in human lung cancer cells. J Exp Clin Cancer Res 2014; 33: 3.

16. Jalving M, Heijink DM, Koornstra JJ, Boersma-van Ek W, Zwart N, Wesseling $\mathrm{J}$ et al. Regulation of TRAIL receptor expression by beta-catenin in colorectal tumours. Carcinogenesis 2014; 35: 1092-1099.

17. Meijer A, Kruyt FA, van der Zee AG, Hollema $H$, Le $P$, ten Hoor KA et al. Nutlin-3 preferentially sensitises wild-type p53-expressing cancer cells to DR5-selective TRAIL over rhTRAIL. Br J Cancer 2013; 109: 2685-2695.

18. Gupta SC, Francis SK, Nair MS, Mo YY, Aggarwal BB. Azadirone, a limonoid tetranortriterpene, induces death receptors and sensitizes human cancer cells to tumor necrosis factor-related apoptosis-inducing ligand (TRAIL) through a p53 protein-independent mechanism: evidence for the role of the ROS-ERK-CHOP-death receptor pathway. J Biol Chem 2013; 288: 32343-32356. 
19. Lee DH, Lee CS, Kim DW, Ae JE, Lee TH. Digitoxin sensitizes glioma cells to TRAILmediated apoptosis by upregulation of death receptor 5 and downregulation of survivin. Anticancer Drugs 2014; 25: 44-52.

20. Ungefroren $H$, Voss M, Jansen M, Roeder C, Henne-Bruns D, Kremer B et al. Human pancreatic adenocarcinomas express Fas and Fas ligand yet are resistant to Fas-mediated apoptosis. Cancer Res 1998; 58: 1741-1749.

21. Abaan OD, Levenson A, Khan O, Furth PA, Uren A, Toretsky JA. PTPL1 is a direct transcriptional target of EWS-FLI1 and modulates Ewing's Sarcoma tumorigenesis. Oncogene 2005; 24: 2715-2722.

22. Steensma DP, Neiger JD, Porcher JC, Keats JJ, Bergsagel PL, Dennis TR et al. Rearrangements and amplification of IER3 (IEX-1) represent a novel and recurrent molecular abnormality in myelodysplastic syndromes. Cancer Res 2009; 69: 7518-7523.

23. Ishida T, Ueda R. Immunopathogenesis of lymphoma: focus on CCR4. Cancer Sci 2011; 102: 44-50.

24. Candi E, Agostini M, Melino G, Bernassola F. How the TP53 family proteins TP63 and TP73 contribute to tumorigenesis: regulators and effectors. Hum Mutat 2014; 35 : 702-714.

25. Reddy RM, Yeow WS, Chua A, Nguyen DM, Baras A, Ziauddin MF et al. Rapid and profound potentiation of Apo2L/TRAIL-mediated cytotoxicity and apoptosis in thoracic cancer cells by the histone deacetylase inhibitor Trichostatin A: the essential role of the mitochondriamediated caspase activation cascade. Apoptosis 2007; 12: 55-71.

26. Zhang J, Zhong Q. Histone deacetylase inhibitors and cell death. Cell Mol Life Sci 2014; 71: 3885-3901.

27. Lopez-Sanchez P, Costas JC, Naveira HF. Paleogenomic record of the extinction of human endogenous retrovirus ERV9. J Virol 2005; 79: 6997-7004.

28. Spierings DC, de Vries EG, Vellenga E, van den Heuvel FA, Koornstra JJ, Wesseling J et al. Tissue distribution of the death ligand TRAIL and its receptors. J Histochem 52: 821-831.

29. Shetty S, Graham BA, Brown JG, Hu X, Vegh-Yarema N, Harding G et al. Transcription factor NF-kappaB differentially regulates death receptor 5 expression involving histone deacetylase 1. Mol Cell Biol 2005; 25: 5404-5416.

30. Fandy TE, Shankar S, Ross DD, Sausville E, Srivastava RK. Interactive effects of HDAC inhibitors and TRAIL on apoptosis are associated with changes in mitochondrial functions and expressions of cell cycle regulatory genes in multiple myeloma. Neoplasia 2005; 7: 646-657.

31. Cao H, Cheng Y, You L, Qian J, Qian W. Homoharringtonine and SAHA synergistically enhance apoptosis in human acute myeloid leukemia cells through upregulation of TRAIL and death receptors. Mol Med Rep 2013; 7: 1838-1844.

32. Singh TR, Shankar S, Srivastava RK. HDAC inhibitors enhance the apoptosis-inducing potential of TRAIL in breast carcinoma. Oncogene 2005; 24: 4609-4623.

33. Kohany $\mathrm{O}$, Gentles AJ, Hankus L, Jurka J. Annotation, submission and screening of repetitive elements in Repbase: RepbaseSubmitter and Censor. BMC Bioinformatics 2006; 7: 474

34. Wu GS, Burns TF, McDonald ER 3rd, Jiang W, Meng R, Krantz ID et al. KILLER/DR5 is a DNA damage-inducible p53-regulated death receptor gene. Nat Genet 1997; 17: 141-143.

35. Takimoto R, El-Deiry WS. Wild-type p53 transactivates the KILLER/DR5 gene through an intronic sequence-specific DNA-binding site. Oncogene 2000; 19: 1735-1743.

36. Koster R, van Vugt MA, Timmer-Bosscha H, Gietema JA, de Jong S. Unravelling mechanisms of cisplatin sensitivity and resistance in testicular cancer. Expert Rev Mol Med 2013; 15: e12.

37. Kelland L. The resurgence of platinum-based cancer chemotherapy. Nat Rev Cancer 2007; 7: 573-584.

38. Rabik CA, Dolan ME. Molecular mechanisms of resistance and toxicity associated with platinating agents. Cancer Treat Rev 2007; 33: 9-23.

39. Sprauten M, Darrah TH, Peterson DR, Campbell ME, Hannigan RE, Cvancarova M et al. Impact of long-term serum platinum concentrations on neuro- and ototoxicity in Cisplatintreated survivors of testicular cancer. Clin Oncol 2012; 30: 300-307.

40. Chou TC. Drug combination studies and their synergy quantification using the Chou-Talalay method. Cancer Res 2010; 70: 440-446.

41. Singh SB, Davis AS, Taylor GA, Deretic V. Human IRGM induces autophagy to eliminate intracellular mycobacteria. Science 2006; 313: 1438-1441.

42. Singh SB, Ornatowski W, Vergne I, Naylor J, Delgado M, Roberts E et al. Human IRGM regulates autophagy and cell-autonomous immunity functions through mitochondria. Nat Cell Biol 2010; 12: 1154-1165.
43. McCarroll SA, Huett A, Kuballa P, Chilewski SD, Landry A, Goyette $P$ et al. Deletion polymorphism upstream of IRGM associated with altered IRGM expression and Crohn's disease. Nat Genet 2008; 40: 1107-1112.

44. Brest $P$, Lapaquette $P$, Souidi M, Lebrigand K, Cesaro A, Vouret-Craviari V et al. A synonymous variant in IRGM alters a binding site for miR-196 and causes deregulation of IRGM-dependent xenophagy in Crohn's disease. Nat Genet 2011; 43: 242-245.

45. Stachel I, Geismann C, Aden K, Deisinger F, Rosenstiel P, Schreiber S et al. Modulation of nuclear factor E2-related factor-2 (Nrf2) activation by the stress response gene immediate early response-3 (IER3) in colonic epithelial cells: a novel mechanism of cellular adaption to inflammatory stress. J Biol Chem 2014; 289: 1917-1929.

46. Hasler R, Kerick M, Mah N, Hultschig C, Richter G, Bretz F et al. Alterations of pre-mRNA splicing in human inflammatory bowel disease. Eur J Cell Biol 2011; 90 603-611.

47. Arlt A, Schafer $\mathrm{H}$. Role of the immediate early response 3 (IER3) gene in cellular stress response, inflammation and tumorigenesis. Eur J Cell Biol 2011; 90: 545-552.

48. Pawlikowska P, Leray I, de Laval B, Guihard S, Kumar R, Rosselli F et al. ATM-dependent expression of IEX-1 controls nuclear accumulation of Mcl-1 and the DNA damage response. Cell Death Differ 2010; 17: 1739-1750.

49. Yang YM, Feng AL, Zhou CJ, Liang XH, Mao HT, Deng BP et al. Aberrant expression of chemokine receptor CCR4 in human gastric cancer contributes to tumor-induced immunosuppression. Cancer Sci 2011; 102: 1264-1271.

50. Lian F, Xing X, Yuan G, Schafer C, Rauser S, Walch A et al. Farnesoid X receptor protects human and murine gastric epithelial cells against inflammation-induced damage. Biochem $J$ 2011; 438: 315-323.

51. Boekelheide K, Lee J, Shipp EB, Richburg JH, Li G. Expression of Fas system-related genes in the testis during development and after toxicant exposure. Toxicol Lett 1998; 102-103: 503-508.

52. Castilla C, Chinchon D, Medina R, Torrubia FJ, Japon MA, Saez C. PTPL1 and PKCdelta contribute to proapoptotic signalling in prostate cancer cells. Cell Death Dis 2013; 4: e576.

53. Costas J, Naveira $\mathrm{H}$. Evolutionary history of the human endogenous retrovirus family ERV9. Mol Biol Evol 2000; 17: 320-330.

54. Wang J, Xie G, Singh M, Ghanbarian AT, Rasko T, Szvetnik A et al. Primate-specific endogenous retrovirus-driven transcription defines naive-like stem cells. Nature 2014; 516: 405-409.

55. Pi W, Yang Z, Wang J, Ruan L, Yu X, Ling J et al. The LTR enhancer of ERV-9 human endogenous retrovirus is active in oocytes and progenitor cells in transgenic zebrafish and humans. Proc Natl Acad Sci USA 2004; 101: 805-810.

56. Yu X, Zhu X, Pi W, Ling J, Ko L, Takeda Y et al. The long terminal repeat (LTR) of ERV-9 human endogenous retrovirus binds to NF-Y in the assembly of an active LTR enhancer complex NF-Y/MZF1/GATA-2. J Biol Chem 2005; 280: 35184-35194.

57. Xu L, Elkahloun AG, Candotti F, Grajkowski A, Beaucage SL, Petricoin EF et al. A novel function of RNAs arising from the long terminal repeat of human endogenous retrovirus 9 in cell cycle arrest. J Virol 2013; 87: 25-36.

58. Liu J, Edagawa M, Goshima H, Inoue M, Yagita H, Liu Z et al. Role of ATF3 in synergistic cancer cell killing by a combination of HDAC inhibitors and agonistic anti-DR5 antibody through ER stress in human colon cancer cells. Biochem Biophys Res Commun 2014; 445 : 320-326.

59. Coureuil M, Ugolin N, Tavernier M, Chevillard S, Barroca V, Fouchet P et al. Puma and Trail/ Dr5 pathways control radiation-induced apoptosis in distinct populations of testicular progenitors. PLOS One 2010; 5: e12134.

60. McKee CM, Ye Y, Richburg JH. Testicular germ cell sensitivity to TRAIL-induced apoptosis is dependent upon p53 expression and is synergistically enhanced by DR5 agonistic antibody treatment. Apoptosis 2006; 11: 2237-2250.

61. Hannah NH, Einhorn LH. Testicular cancer-discoveries and updates. N Engl J Med 2014; 371: 2005-2016.

62. Oosterhuis JW, Looijenga LH. Testicular germ-cell tumours in a broader perspective. Nat Rev Cancer 2005; 5: 210-222.

63. Mann BS, Johnson JR, Cohen MH, Justice R, Pazdur R. FDA approval summary: vorinostat for treatment of advanced primary cutaneous T-cell lymphoma. Oncologist 2007; 12: 1247-1252.

64. Goodman M. The genomic record of Humankind's evolutionary roots. Am J Hum Genet 1999; 64: 31-39. 